\title{
Interferon-Gamma and Interlukin-4 Patterns in BALB/c Mice Suffering From Cutaneous Leishmaniasis Treated With Cantharidin
}

\author{
Yahya Maroufi ${ }^{1}$; Fatemeh Ghaffarifar ${ }^{2, *}$; Abdolhosein Dalimi ${ }^{2}$; Zohreh Sharifi ${ }^{3}$ \\ ${ }^{1}$ Department of Parasitology, Faculty of Medical Sciences, Zabol University of Medical Sciences, Zabol, IR Iran \\ ${ }^{2}$ Department of Parasitology, Faculty of Medical Sciences, Tarbiat Modares University, Tehran, IR Iran \\ 3 Department of Virology, Iranian Blood Transfusion organization, Tehran, IR Iran \\ ${ }^{*}$ Corresponding author: Fatemeh Ghaffarifar, Department of Parasitology, Faculty of Medical Sciences, Tarbiat Modares University, Tehran, IR Iran. Tel: +98-2182884553, Fax: +98- \\ 2188006544, E-mail: ghafarif@modares.ac.ir
}

Received: March 4, 2013; Revised: June 1, 2013; Accepted: June 16, 2013

\begin{abstract}
Background: Cutaneous leishmaniasis is a health problem in the world. Lesions should be treated on cosmetically or functionally important sites, such as the face and hands. Cantharidin is a terpenoid compound produced naturally by beetles of Meloidae and Oedemeridae families.

Objectives: The current study aimed to investigate the effect of cantharidin on Cutaneous Leishmaniasis (CL) lesions and IFN-Y and IL-4 patterns in infected BALB/c mice.

Materials and Methods: Infected BALB/c mice were divided into five groups as: untreated (control group), eucerin-treated and $0.05 \%$, $0.1 \%$ and $0.5 \%$ cantharidin-treated. Lesions diameter was measured by Vernier caliper every three days for four weeks. Cytokines levels were measured by enzyme-linked immunosorbent assay (ELISA) using U-CyTech kit.

Results: The results indicated that treatment with cantharidin exacerbates lesions compared with the controls, except for 0.05\% cantharidin dose that restrained lesion growth significantly. Interferon gamma level in cantharidin-treated groups was significantly less than that of the control group. But interlukin-4 level was similar among the groups.

Conclusions: The current study results indicated that high doses of cantharidin exacerbates leishmaniasis lesion, but low dose of cantharidin inhibits lesion growth.
\end{abstract}

Keywords:Mice, Inbred BALB/c; Cantharidin; Leishmaniasis, Cutaneous; Interferon-gamma

\section{Background}

Cutaneous leishmaniasis is one of the health problems in the world. About 12 million people are infected by Leishmania in 88 countries around world (1.5 to 2 million new cases each year). Cutaneous Leishmaniasis (CL) is caused by variable species of Leishmania such as Leishmania major. Clinical manifestation of CL is characterized by ulcerative skin lesions developing at the site of sandfly bite. Lesions should be treated on cosmetically or functionally important sites, such as the face and hands. The pentavalent antimony sodium stibogluconate and meglumine antimoniate are the main chemotherapy. In addition to side effects, resistance and relapse happen $(1,2)$. Cantharidin is a terpenoid compound produced naturally by families of Meloidae and Oedemeridae beetles (3). Chinese have used it as a traditional medicine about 2000 years ago (4). It has been used to treat wart and cutaneous lesions $(4,5)$. Hakim Jorjani used cantharidin to treat wart, hair loss, rabidity and black nails (6).

Cantharidin is a protein phosphatase 1 and 2A (PP1 \& 2A) inhibitor, and PP1 and $2 \mathrm{~A}$ are primary targets of cantharidin $(3,7,8)$. There are some studies about the effect of canthari- din on several cancer cells (9-12). Cantharidin induces apoptosis in cancer cells and also in L. major in vitro and in vivo (13-15). In experimental leishmaniasis, immunity is principally mediated by T lymphocytes. T helper (Th1)and Th2 cells can be identified by the cytokines they secrete: Th1 cells secrete activators of cell-mediated immunity such as IFN- $\gamma$, while Th2 cells secrete cytokines such as IL-4, which promote antibody responses (16). Interferon-gamma (IFN- $\Upsilon$ ) is the essential cytokine for inducing protective immunity against cutaneous leishmaniasis. IFN- $\Upsilon$ kills the parasite and causes protective immunity in both human and murine cutaneous leishmaniasis $(16,17)$. But, BALB/c mice that develop a typical Th2 response are highly susceptible to leishmaniasis (18).

\section{Objectives}

The current study aimed to investigate the effect of cantharidin on CL lesions and Interferon-gamma (IFN-Y) (as an indicator of Th1-type response), and Interlukin-4 (IL-4) (as a Th2-type response indicator) patterns in BALB/c mice infected with L. major. 
MaroufiYetal.

\begin{tabular}{lll}
\hline \multicolumn{1}{l}{ Table1. Lesion Size in Different Groups Before and After Treatment ${ }^{\mathrm{a}}$} & \\
\hline Groups & Before Treatment & After Treatment \\
\hline Untreated (control) & $2.50 \pm 0.50$ & $3.70 \pm 0.18$ \\
Eucerin-treated & $5.66 \pm 1.33$ & $7.19 \pm 0.59$ \\
Cantharidin-treated & & \\
\multicolumn{1}{c}{$0.05 \%$} & $4.6 \pm 0.60$ & $4.54 \pm 0.19$ \\
\hline $0.1 \%$ & $5.7 \pm 1.00$ & $6.13 \pm 0.33$ \\
\hline $0.5 \%$ & $7.33 \pm 0.44$ & $10.28 \pm 0.29$ \\
\hline
\end{tabular}

${ }^{\mathrm{a}}$ Data showed as Mean $\pm \mathrm{SD}$.

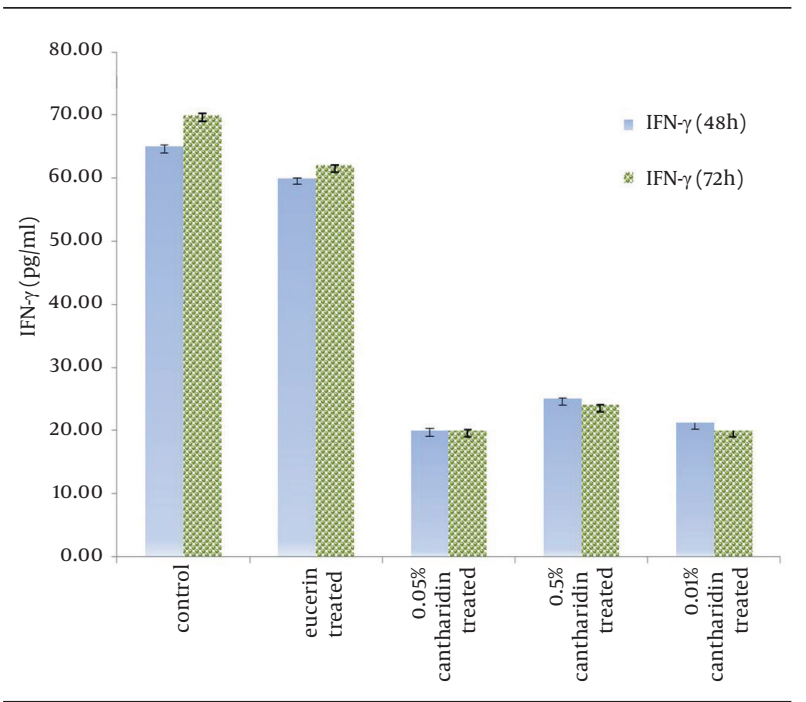

Figure 1. IFN- $\Upsilon$ Level in Lymphocytes Separated From Spleen in different Groups After 48 and 72 Hours Following Treated With Soluble Leishmania Antigen

\section{Materials and Methods}

\subsection{Animals}

Six eight-week-old female BALB/c mice were purchased from Razi Institute (Tehran, Iran).They were fed standard mouse chow and ad libitum water.

\subsection{Parasites}

L. major MRHO/IR/75/ER was used in this study, the parasite was maintained by passage through BALB/c mice and culture in NNN medium.

\subsection{Mice Infecting}

Thirty female BALB/c mice were infected by injecting $2 \times 10^{6} / \mathrm{mL}$ stationary phase $L$. major promastigotes into the base of tail. The mice were divided into five groups as: untreated (control), eucerin-treated, 0.05\%, 0.1\% and 0.5\% cantharidin-treated groups.

\subsection{Cantharidin Preparation}

Cantharidin was purchased from Sigma (Germany). It was dissolved in eucerin as ointment base. Cantharidin ointment was prepared in three doses $(0.05 \%, 0.1 \%$ and $0.5 \%$ ). Cantharidin was used once a day for four weeks topically.

\subsection{Lesion Size and Cytokines Level Measurement}

Cutaneous leishmaniasis lesions diameter was measured by Vernier caliper every three days for four weeks. To measure IFN- $Y$ and IL-4 level, mice were killed at the end of treatment. Spleen lymphocytes were extracted and $1 \times 10^{6} / \mathrm{mL}$ lymphocytes was cultured in 24-well plates in the RPMI-1640 cell culture medium (GibCo, USA) containing $10 \%$ heat-inactivated fetal calf serum (FCS; GibCo, USA) and $100 \mathrm{U} / \mathrm{mL}$ penicillin, $100 \mu \mathrm{g} / \mathrm{mL}$ streptomycin (Sigma, Germany). Soluble Leishmania antigens (SLA) were obtained by resuspending $L$. major promastigotes in sterile PBS at a concentration about 108 parasite/mL. Parasites were lysed by five freeze-thawing cycles, and then centrifuged at $4^{\circ} \mathrm{C}$ for 15 minutes. The supernatant was collected and protein concentration was measured by Bradford assay. Soluble Leishmania antigens, by concentration of $20 \mu \mathrm{g} / \mathrm{mL}$, were added to wells and then plates incubated in $5 \% \mathrm{CO}_{2}$ at $37^{\circ} \mathrm{C}$. Supernatants were collected after 48 and 72 hours and stored at $-80^{\circ} \mathrm{C}$ until use. Cytokines levels were measured by enzyme-linked immunosorbent assay (ELISA) using U-CyTech (bioscience, Netherlands) kit according to the manufacturer's instructions.

\subsection{Statistical Analysis}

Data were analyzed using a one-way analysis of variance (ANOVA). Results were shown as mean \pm standard deviation (SD). All statistical analyses were performed using SPSS 16 software for Windows.

\section{Results}

\subsection{Lesion Size}

Table 1 shows the lesion size mean before and after treat 


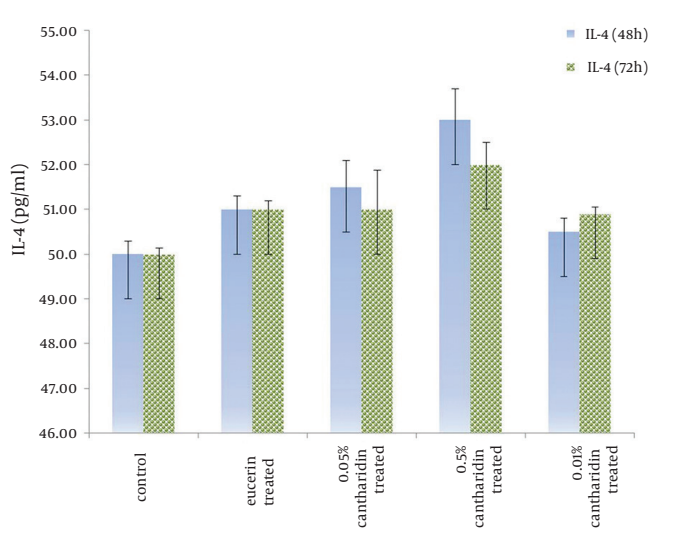

Figure 2. IL-4 Level in Lymphocytes Separated From Spleen in Different Groups After 48 and 72 Hous Following Treated With Soluble Leishmania Antigen

ment in different groups. The results of the current study indicated that treatment with cantharidin exacerbates lesions compared with the controls, excluding $0.05 \%$ dose. But 0.05\% cantharidin restrained lesion growth significantly $(\mathrm{P}<0.05)$.

\subsection{IFN-Y and IL-4 Pattern}

Control group and eucerin-treated group produced high levels of IFN- $\Upsilon$, but cantharidin-treated groups showed low levels of IFN- $\Upsilon$, significantly $(\mathrm{P}<0.05)$ (Figure 1). There was no significant difference between IFN- $\Upsilon$ levels in eucerin-treated and control groups. Interlukin-4 level was similar among the groups (Figure 2).

\section{Discussion}

This is the first report showing the effect of cantharidin on IFN- $Y$ and IL-4 in cutaneous leishmaniasis. Results showed that cantharidin exacerbates CL lesion, except for $0.05 \%$ cantharidin. Cantharidin suppresses Th1 type response by inhibiting IFN- $\Upsilon$ production, but it has no effect on IL-4. In the current study, treatment with $0.05 \%$ cantharidin restrained lesion growth, but it was unable to increase IFN- $\Upsilon$ production. Some studies indicate the inflammatory reaction in blister location with lymphocytes and macrophages infiltration. Neutrophils are primary antimicrobial effector cells, and their main function is affecting phagocytosis and destroying invading pathogens. Following L. major transmission, neutrophils were observed capturing parasites rapidly and efficiently. Neutrophils produce and secret myeloperoxidase causing tissue damage (19-21). Cantharidin induces neutrophils infiltration into the blister site in the first 24 hours and macrophages from 24 to 72 hours $(19,21)$. Infiltrating neutrophils did not destroy the parasite. Dendritic cells produce IL-12, which drives the generation of Th1 cells. Th1 cells in turn activate macrophages to increase inducible nitric oxide synthases (iNOS) and nitric oxide (NO) production, which results in killing the intracellular parasites (20). Cantharidin arrests dendritic cells proliferation and IFN-Y production (22). Norcantharidin, demethylated form of cantharidin, inhibits peripheral blood mononuclear cells (PBMC) proliferation in vitro (23). Also it can inhibit IL-12 production in human leukemic Jurket T cells, but doses less than $2 \mu \mathrm{g} / \mathrm{mL}$ induce IL-12 production (24).

The current study results indicate that high doses of cantharidin exacerbates lesion due to Th1-type response, therefore inhibiting IFN- $\Upsilon$ production. But lesion growth in the group treated with $0.05 \%$ cantharidin was restrained. It can be supposed that cantharidin with low dose accelerates lesion healing.

\section{Acknowledgements}

This study was performed as $\mathrm{PhD}$ thesis and was supported by Tarbiat Modares University.

\section{Authors' Contribution}

The funding organizations are academic institutions and had no role in the design and conduct of the study; collection, management, and analysis of the data; or preparation, review, and approval of the manuscript. Yahya Maroufi carried out the design and coordinated the study, participated in all experiments and prepared the manuscript. Fatemeh Ghaffarifar was the supervisor of this study, Abdolhosein Dalimi and Zohreh Sharifi provided assistance in the design of the study, coordinated and participated in manuscript preparation. All authors have read and approved the content of the manuscript.

\section{Financial Disclosure}

The authors declare no conflict of interest.

\section{Funding Support}

Authors wish to thank Tarbiat Modares University of Medical Sciences for the financial support.

\section{References}

1. Hepburn NC. Cutaneous leishmaniasis. Clin Exp Dermatol. 2000;25(5):363-70.

2. Reithinger R, Dujardin JC, Louzir H, Pirmez C, Alexander B, Brooker S. Cutaneous leishmaniasis. Lancet Infect Dis. 2007;7(9):581-96.

3. Bonness K, Aragon IV, Rutland B, Ofori-Acquah S, Dean NM, Honkanen RE. Cantharidin-induced mitotic arrest is associated with the formation of aberrant mitotic spindles and lagging chromosomes resulting, in part, from the suppression of PP2Aalpha. Mol CancerTher. 2006;5(11):2727-36.

4. Moed L, Shwayder TA, Chang MW. Cantharidin revisited: a blistering defense of an ancient medicine. Arch Dermatol. 2001;137(10):1357-60.

5. Deponte M. Programmed cell death in protists. Biochim Biophys Acta. 2008;1783(7):1396-405.

6. Yousefi M. From blisters beetle untile cantharidin. Darmangar. 2004;3:36-9. 
7. Li YM, Casida JE. Cantharidin-binding protein: identification as protein phosphatase 2A.Proc NatlAcad SciUSA.1992;89(24):1186770.

8. Eldridge GD, St Lawrence JS, Little CE, Shelby MC, Brasfield TL. Barriers to condom use and barrier method preferences among lowincome African-American women. Women Health. 1995;23(1):7389.

9. Wang XH, Yin YQ, Sui CG, Meng FD, Ma P, Jiang YH. Inhibitory effect of Cantharidin on proliferation of A549 cells. Chin J Cancer Res. 2007;19(4):283-6.

10. Sagawa M, Nakazato T, Uchida H, Ikeda Y, Kizaki M. Cantharidin induces apoptosis of human multiple myeloma cells via inhibition of the JAK/STAT pathway. Cancer Sci. 2008;99(9):1820-6.

11. Fan YZ, Fu JY, Zhao ZM, Chen CQ. Influence of norcantharidin on proliferation, proliferation-related gene proteins proliferating cell nuclear antigen and Ki-67 of human gallbladder carcinoma GBC-SD cells. Hepatobiliary Pancreat Dis Int. 2004;3(4):603-7.

12. Rauh R, Kahl S, Boechzelt H, Bauer R, Kaina B, Efferth T. Molecular biology of cantharidin in cancer cells. Chin Med. 2007;2:8.

13. Marufi Y, Ghaffarifar F, Dalimi A, Sharifi Z, Hassan ZM. Cantharidin-induced apoptosis in Leishmania major promastigotes and macrophages infected by Leishmania major amastigotes invitro. J Mazandaran Univ Med Sci. 2012;22(87):33-40.

14. Maroufi Y, Ghaffarifar F, Dalimi A, Sharifi Z, Hasan Z. A study on the cytotoxic effect of cantharidin on Leishmania major promastigote and amastigote survival in vitro. Feyz J Kashan Univ Med Sci. 2012;16(5):406-13.

15. Maroufi Y, Ghaffarifar F, Dalimi A, Sharifi Z, Hasan Z. Effect of Cantharidin on Apoptosis of the Leishmania major and on Parasite Load in BALB/c Mice. Res J Parasitol. 2013;8(1):In Press.
16. Sharma U, Singh S. Immunobiology of leishmaniasis. Indian JExp Biol. 2009;47(6):412-23.

17. Rosas LE, Keiser T, Pyles R, Durbin J, Satoskar AR. Development of protective immunity against cutaneous leishmaniasis is dependent on STAT1-mediated IFN signaling pathway. Eur J Immunol. 2003;33(7):1799-805.

18. Wang ZE, Reiner SL, Zheng S, Dalton DK, Locksley RM. CD4+ effector cells default to the Th2 pathway in interferon gammadeficient mice infected with Leishmania major. J Exp Med. 1994;179(4):1367-71

19. Dinh PH, Corraza F, Mestdagh K, Kassengera Z, Doyen V, Michel O. Validation of the cantharidin-induced skin blister as an in vivo model of inflammation. Br JClin Pharmacol. 2011;72(6):912-20.

20. Nylen S, Gautam S. Immunological perspectives of leishmaniasis. J Glob Infect Dis. 2010;2(2):135-46.

21. Zou XJ, Liu HP, Cheng T, Shi L, Zu P, Zhang YJ. [A technique for investigating the component of cantharidin blisters by flow cytometry]. Zhong Yao Cai. 2007;30(7):823-5.

22. Hsieh CH, Huang YC, Tsai TH, Chen YJ. Cantharidin modulates development of human monocyte-derived dendritic cells. Toxicol In Vitro. 2011;25(8):1740-7.

23. Chen YC, Chang SC, Wu MH, Chuang KA, Wu JY, Tsai WJ, et al Norcantharidin reduced cyclins and cytokines production in human peripheral blood mononuclear cells. Life Sci. 2009;84(7 8):218-26.

24. Liao HF, Chen YJ, Chou CH, Wang FW, Kuo CD. Norcantharidin induces cell cycle arrest and inhibits progression of human leukemic Jurkat $\mathrm{T}$ cells through mitogen-activated protein kinasemediated regulation of interleukin-2 production. Toxicol In Vitro. 2011;25(1):206-12. 